\title{
Innovative cooling strategies: Dairy cow responses and water and energy use
}

\author{
Alycia M. Drwencke, ${ }^{1}$ Grazyne Tresoldi, ${ }^{1,2} \odot$ Matthew M. Stevens, ${ }^{3}$ Vinod Narayanan, ${ }^{3,4}$ Angelica V. Carrazco, ${ }^{5}$ \\ Frank M. Mitloehner, ${ }^{5}{ }^{\oplus}$ Theresa E. Pistochini, ${ }^{3}$ and Cassandra B. Tucker ${ }^{1 *}$ (우 \\ ${ }^{1}$ Center for Animal Welfare, Department of Animal Science, University of California, Davis 95616 \\ ${ }^{2}$ College of Agriculture, California State University, Chico 95929 \\ ${ }^{3}$ Western Cooling Efficiency Center, University of California, Davis 95616 \\ ${ }^{4}$ Department of Mechanical and Aerospace Engineering, University of California, Davis 95616 \\ ${ }^{5}$ Department of Animal Science, University of California, Davis 95616
}

\begin{abstract}
Producers in the western United States commonly use spray water at the feed bunk and fans in the lying area to mitigate heat stress in dairy cows. Often, spray water cycles on and off with fans turning on when a preset air temperature is reached. Although this method can be effective, innovative strategies are needed to reduce water and energy use. We evaluated the effectiveness and resource efficiency of 4 cooling treatments on behavioral and physiological responses in dairy cows housed in a freestall barn: (1) conductive cooling in which mats with recirculating evaporatively cooled water were buried under sand bedding (Mat; activated at $\left.18.9^{\circ} \mathrm{C}\right) ;(2)$ targeted convective cooling in which evaporatively cooled air was directed toward the cows through fabric ducts with nozzles at both the feed bunk and lying areas (Targeted Air; activated at $22^{\circ} \mathrm{C}$ ); (3) evaporative cooling, with spray water in the feed area and fan over the freestalls (Baseline; activated at $22^{\circ} \mathrm{C}$ ); and (4) evaporative cooling with half the amount of spray water used in the Baseline and the fan moved to the feed bunk (Optimized Baseline; activated at $22^{\circ} \mathrm{C}$ ). In a crossover design, 8 groups of cows (4/ group) producing an average ( \pm standard deviation) of $37.5 \pm 4.5 \mathrm{~kg} / \mathrm{d}$ of milk were tested for $3 \mathrm{~d}$ per treatment. For ethical reasons, beginning at $30^{\circ} \mathrm{C}$, the Mat treatment was supplemented with Baseline cooling and the Targeted Air treatment had spray water at the Optimized Baseline rate. We recorded body temperature, posture, and location within the pen every $3 \mathrm{~min}$ for $24 \mathrm{~h} / \mathrm{d}$, and respiration rates every $30 \mathrm{~min}$ daily from 1000 to $1900 \mathrm{~h}$. Daily air temperature averaged $( \pm \mathrm{SD})$ $26.3 \pm 7.1^{\circ} \mathrm{C}$ during $24 \mathrm{~h}$ and $33.3 \pm 4^{\circ} \mathrm{C}$ from 1000 to $1900 \mathrm{~h}$. We used pairwise comparisons of each treat-
\end{abstract}

Received July 29, 2019.

Accepted February 2, 2020.

*Corresponding author: cbtucker@ucdavis.edu ment to Baseline to evaluate response variables. Milk production did not differ across treatments, nor did time spent lying (51 $\pm 2 \% / \mathrm{d}$ on average). Respiration rates did not differ across treatments overall $(61 \pm 3$ breaths/min), but on an hourly basis, cows in the Mat treatment had a significantly higher rate than those in Baseline, at h 10 and 11 (70 vs. 58-59 breaths/min). Body temperature averaged $38.7 \pm 0.05^{\circ} \mathrm{C}$ across treatments and was 0.2 to $0.3^{\circ} \mathrm{C}$ higher in the Mat treatment than in Baseline at $\mathrm{h} \mathrm{10}, 11,20,21$, and 22. These results collectively indicate that the Mat treatment did not effectively reduce indicators of heat load compared with Baseline. In contrast, Targeted Air and Optimized Baseline were both effective but differed in aspects of efficiency. Targeted Air used the least amount of water but the most energy of all options tested. In conclusion, more efficient heat abatement options were identified, particularly an Optimized Baseline strategy, which cut water use in half, required the same amount of energy as the Baseline, and maintained similar physiological and behavioral responses in cows.

Key words: heat load, heat stress, spray water, conductive cooling, targeted convective cooling

\section{INTRODUCTION}

The cumulative effects of heat stress compromise animal welfare and decrease the profitability of the dairy industry. These effects from hot ambient conditions can alter the physiological state and behavior of a dairy cow by increasing cow respiration rate $(\mathbf{R R}$; Tresoldi et al., 2016) and body temperature (BT, as reviewed by West, 2003) and by decreasing milk yield (Ravagnolo et al., 2000; West et al., 2003), time spent lying (Cook et al., 2007) and ruminating (Abeni and Galli, 2017). To mitigate these negative effects, successful heat transfer away from the cow needs to occur.

Currently, spray water and fans, in addition to shade, are the most commonly used forms of heat abatement in the United States (USDA, 2014). Although these 
systems can be effective, they also use large quantities of water and electricity, which can affect profitability and sustainability of the dairy industry (von Keyserlingk et al., 2013). In addition, the cost of electricity is continuing to rise (Collier et al., 2006) and water availability is decreasing due to changed rainfall patterns, particularly in California (Rosenstock et al., 2006). These changes in price and availability also increase the need for more efficient heat abatement that uses less water and energy.

Modes by which heat transfer occurs include conduction, convection, and radiation. Convective cooling involves heat transfer to cooler air that surrounds the body of the cow, allowing her to dissipate heat (reviewed by Kadzere et al., 2002). Evaporative cooling is a particularly effective mode of convective heat transfer due to the amount of heat that can be removed by changing the phase of liquid water to vapor. Indeed, as described above, evaporative cooling is widely used on dairies in the form of spray water and fans. Conductive cooling uses the transfer of heat from the cow to the surrounding media the animal comes in contact with, often while lying down (reviewed by Kadzere et al., 2002).

Relatively novel heat abatement methods that have been tested but not widely adopted include air conditioning, which is a form of convective cooling (Hahn et al., 1969), and conductive cooling (Bastian et al., 2003; Ortiz et al., 2015; Perano et al., 2015). These alternatives serve as starting points for improving efficiency. Although air conditioning an entire barn is not a viable option due to costs (Hahn et al., 1969), other forms of convective cooling could be assessed for effectiveness and efficiency. For conductive cooling, the amount of heat transfer depends on the conductive properties and temperature of the media (Schmidt-Nielsen, 1964; Esmay, 1969; Ortiz et al., 2015), but on the whole, this approach shows promise as an effective and efficient option (Bastian et al., 2003; Ortiz et al., 2015; Perano et al., 2015). However, synthetic mattresses that may be used with this approach are a key risk factor for lesions (Kester et al., 2014), warranting further evaluation of conductive cooling in deep bedded systems.

In addition to finding novel cooling methods, we can also enhance the efficiency of the popular heat abatement strategy of spray water and fans. Tresoldi et al. (2017) showed that a large variation exists in the amount of water used to cool cattle on California dairies that use spray (2.3-25.7 L/cow per hour). These dairies also varied in their effectiveness of cow cooling. For example, average daily $\mathrm{RR}$ were between 65 and 95 breaths/min, but the amount of water used was not consistently related to cow response. The reasons for variation may be more complicated, as the amount of water used is influenced by spray duration, flow rate, and spray frequency. Previous studies have examined the duration of spray needed to cool cattle, but suggestions range from $30 \mathrm{~s}$ to 3 min (Flamenbaum et al., 1986; Tresoldi et al., 2018a). Tresoldi et al. (2018a) also report that it only takes $30 \mathrm{~s}$ to soak a cow's coat. This finding indicates that it may be possible to cool cows with less water than when soaking cows for 1.5 or $3 \mathrm{~min}$ as done by Tresoldi et al. (2018a). Also, others have found that increasing spray frequency by reducing the amount of time off lowers the microclimate air temperature (AT), temperature-humidity index (THI), and cow heat load (Brouk et al., 2003b; Tresoldi et al., 2018b). However, despite the advantages, spraying water more frequently increases the quantity of water used, which compromises resource efficiency. Furthermore, on windy days, for example, the cow coat dries faster and leg surface temperature and RR are reduced (Tresoldi et al., 2018a). Thus, additional cooling benefits could potentially be obtained by offering airflow near the spray water. Indeed, some producers locate fans near the feed, as airflow close to the spray could promote evaporative cooling during the off cycle. The most efficient spray method requires taking spray duration, frequency, and air speed into consideration.

The objective of this study was to evaluate innovative cooling strategies for their effectiveness in mitigating heat stress in lactating dairy cattle, as well as their water and energy efficiency in comparison with the popular approach of spray water at the feed bunk and fans over the freestalls. We predicted that if heat abatement was effective, cows would maintain similar physiological and behavioral responses to the baseline approach under all summer ambient conditions in California. In addition, we expected our innovative cooling strategies to use less water and energy than the popular approach.

\section{MATERIALS AND METHODS}

\section{Animals and Housing}

This study was carried out between June and September 2017 at the University of California (UC), Davis Dairy Teaching and Research Facility. All procedures were approved by the UC Davis Institutional Animal Care and Use Committee. Four cohorts of 8 lactating cows were used. Each cohort was composed of 2 groups, with 3 Holsteins and 1 Jersey per group (6 Holsteins and 2 Jerseys per cohort) that were balanced for milk production ( $\mathrm{n}=8$ groups total). Cows were selected based on a daily milk yield $>30 \mathrm{~kg}$ and confirmed pregnancy. Sample size of the study was based on the availability of cows meeting these criteria. 


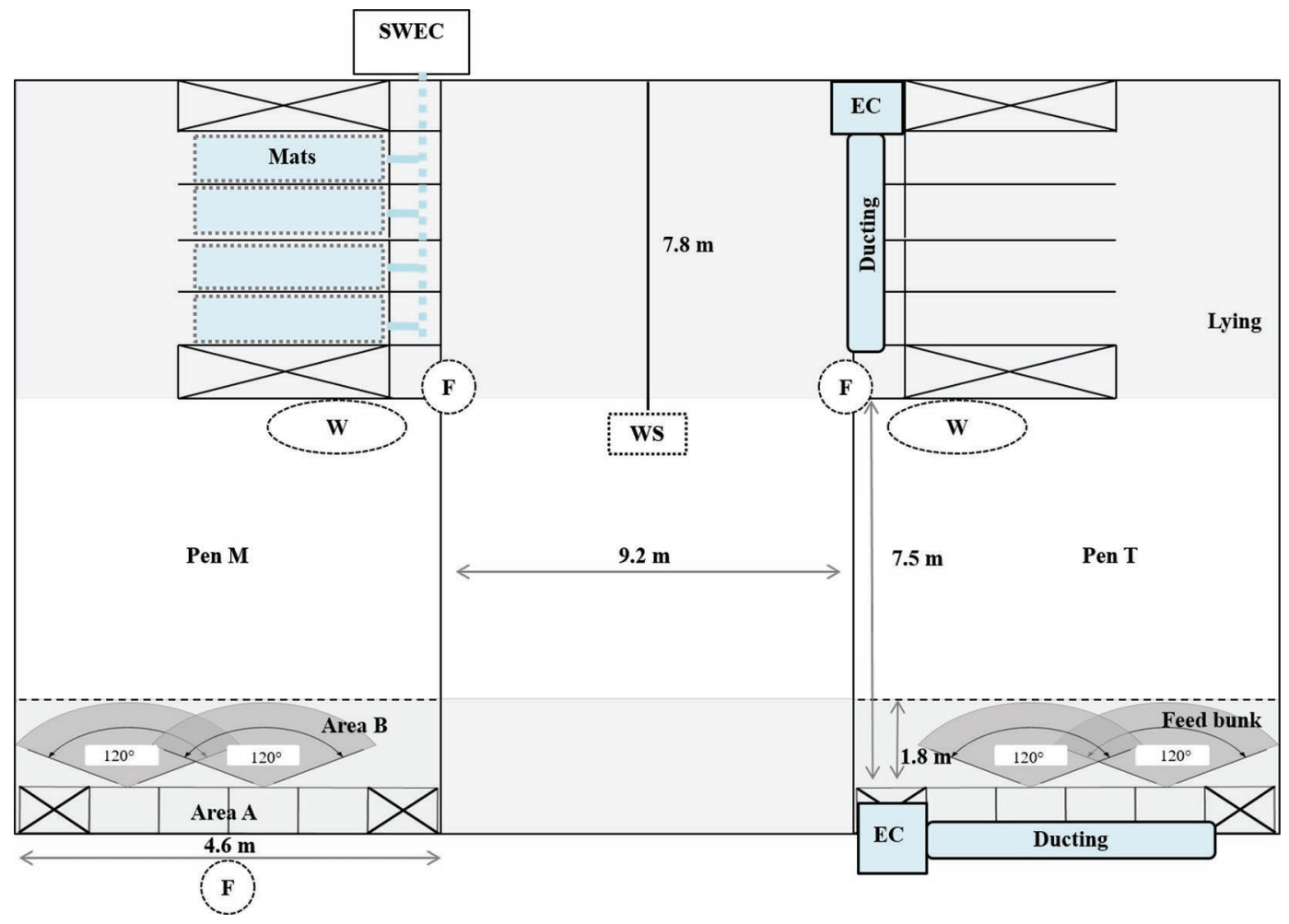

Figure 1. Pen design during the study. Each pen ( $\mathrm{M}$ or $\mathrm{T}$ ) operated 2 heat abatement strategies and offered access to 4 freestall beds under a steel open-sided barn, an automatically refilled water trough, and 4 shaded head gates. Both pens were used simultaneously for 4 cows at a time. Mats were buried below the sand and ducting was attached to the evaporative coolers to direct air on to cows' withers and back. F = fan; $\mathrm{W}=$ water trough; $\mathrm{WS}=$ weather station; $\mathrm{EC}=$ evaporative cooler; $\mathrm{SWEC}=$ sub-wet bulb evaporative chiller.

Two pens were used simultaneously and labeled as $\mathrm{M}$ and $\mathrm{T}$ (Figure 1), each housing 1 group. Each group had free access to an automatically filled water trough placed by 4 shaded sand freestall beds beneath a steel open-sided barn, located $7.5 \mathrm{~m}$ from the shaded feed bunk that was approximately $4.6 \mathrm{~m}$ long with 4 head gates. Each feed bunk was fitted with a single waterline composed of a solenoid, a $517-\mathrm{kPa}$ pressure relief valve (McMaster-Carr, Santa Fe Springs, CA) and 2 spray nozzles (TF-VP 7.5., Turbo FloodJet wide angle flat spray tip; Spraying Systems Co., Wheaton, IL). One adjustable pressure regulator (PR 15-75; McMasterCarr) was used for both feed bunks. The spray nozzles, approximately $1.7 \mathrm{~m}$ above the ground and $1.7 \mathrm{~m}$ apart, were angled to soak the cows' back from the withers when feeding, reaching up to $1.8 \mathrm{~m}$ away from the feed bunk. To prevent airflow movement and spray water drift, pens were divided by removable fencing panels (Power River, Provo, UT), plywood sheets 7.8 $\mathrm{m}$ long $\times 2.3 \mathrm{~m}$ tall in the shelter area and $1.8 \mathrm{~m}$ long $\times 2.3 \mathrm{~m}$ tall near the feed bunk, and an empty pen approximately $9.2 \mathrm{~m}$ in width. The water pressure $( \pm \mathrm{SD}$ throughout the materials and methods) was $262 \pm 22$
$\mathrm{kPa}$. At this pressure, the flow rate was 4.4 to $4.6 \mathrm{~L} /$ min per nozzle, which was measured at the beginning of the study by a catch and weigh method. The water pressure, temperature, and flow rate delivered to each pen through the sprayers were measured every minute using sensors (Omega PX-300-50GV; Omega NPT Plug Thermistor TH-44004-1/4; Omega FTB4607 respectively; Omega Engineering Inc., Norwalk, CT) and logged by a data acquisition system (Datataker DT80, Thermo Fisher Scientific, Waltham, MA).

Cows were fed TMR ad libitum 4 times daily, at approximately 0400, 1000, 1600, and 2200 h. Milking occurred twice a day at 0400 and $1600 \mathrm{~h}$, with cooling provided in the afternoon with spray water and a fan in the holding area and fans provided in the parlor. The holding area spray water started on a cycle of $2 \mathrm{~min}$ on $/ 10$ min off at an AT of $23.8^{\circ} \mathrm{C}$. For $\mathrm{AT} \geq 30.6^{\circ} \mathrm{C}$, the spray water cycling increased to $3 \mathrm{~min}$ on $/ 2 \mathrm{~min}$ off. The spray cycles interpolated between the 2 set points for AT between $23.8^{\circ} \mathrm{C}$ and $30.6^{\circ} \mathrm{C}(\mathrm{C}-440 \mathrm{~S}$ Controller, Edstrom, Waterford, WI). Milk production data were collected through DairyComp 305 (Valley Agricultural Software, Tulare, CA). 


\section{Experimental Design}

Four treatments were tested: Baseline, Optimized Baseline, Targeted Air, and Mat. Baseline consisted of a fan (91.4-cm diameter Schaefer Barn Kooler, Gardner/ Rossi Company, Ceres, CA) $2.1 \mathrm{~m}$ above the ground in the freestall area and spray water at the feed bunk, a common approach to heat abatement in California. Spray water was on for $1.5 \mathrm{~min}$ and off for 6 min each cycle, and the fan ran continuously when $\mathrm{AT} \geq 22.2^{\circ} \mathrm{C}$. The fan was positioned to serve 12 beds, but cows only had access to 4 . This was considered in calculations of energy use.

Optimized Baseline was comparable to the Baseline, except the fan was placed $1.2 \mathrm{~m}$ from the feed bunk at a height of $3 \mathrm{~m}$ and spray water was on for $0.5 \mathrm{~min}$ and off for $4.5 \mathrm{~min}$ when $\mathrm{AT} \geq 22.2^{\circ} \mathrm{C}$. This treatment was labeled "optimized" because it represents our current thinking about the most practical ways to improve energy and water efficiency using common technology. The fan was assumed to serve 12 head gates, when calculating energy use.

The Targeted Air treatment was composed of fabric ducts (Fabric Air, Herfølge, Denmark) delivering evaporatively cooled air, with jets targeted at the cows in the feed and freestall areas. Although evaporative cooling has previously been demonstrated for cooling livestock, it has generally been studied in enclosed conditioned structures. In this study, an open-air environment was used.

The evaporatively cooled air averaged $21 \pm 3.7^{\circ} \mathrm{C}$. The ducts were approximately $4.1 \mathrm{~m}$ long and located $2 \mathrm{~m}$ above the feed bunk and $2.3 \mathrm{~m}$ above the freestalls. Each duct had 4 nozzles with a diameter of $12.7 \mathrm{~cm}$. The evaporatively cooled air exited with an average velocity of $8.6 \mathrm{~m} / \mathrm{s}$ onto the cows' withers and back at each head gate and freestall. The evaporative cooler (model TH3800C, Phoenix Manufacturing, Phoenix, $\mathrm{AZ}$ ) turned on when $\mathrm{AT} \geq 22.2^{\circ} \mathrm{C}$.

The Mat treatment used conductive cooling with plastic mats (Fafco, Chico, CA) buried in the freestall areas approximately $10.2 \mathrm{~cm}$ below the sand. Two other demonstrations of the cooling mats are known; in one case, the chilled water source was ground-temperature water from a well (once-through cooling; Turlock Irrigation District, 2010), and in the second case, the chilled water was recirculated through a mechanical chiller (Southern California Edison, 2014). The strategy using once-through cooling with well water resulted in poor water-use efficiency, whereas use of the mechanical chiller had poor energy efficiency. In this application, a novel sub-wet bulb evaporative chiller (SWEC; Integrated Comfort, Sacramento, CA) was used to evaporatively cool circulating water averaging $18.8 \pm$ $0.9^{\circ} \mathrm{C}$. The SWEC turned on earlier than the other treatments (when $\mathrm{AT}$ was $\geq 18.9^{\circ} \mathrm{C}$ ) to allow for the ground temperature surrounding the mats to stabilize by the time AT was $\geq 22.2^{\circ} \mathrm{C}$. The SWEC was capable of cooling water to a temperature below the outdoor wet bulb temperature through a series of heat exchangers and evaporative media. It was designed with the capacity to cool 10 mats, so a supplemental electrical resistance heater (25-150-1021 Universal Flo-Thru Heater Assembly, SpaGuts, Anaheim, CA) was used to simulate a load of 6 additional cows. Chilled water was pumped from the SWEC in parallel to the buried mats and heater. The heater regulated water temperature to match the temperature of the water returning from the mats to accurately simulate the load of additional cows.

For ethical reasons, when AT was $\geq 30^{\circ} \mathrm{C}$, we supplemented cooling strategies for the Targeted Air and Mat treatments (Table 1). This threshold was determined by observing signs of panting during a pilot phase of this study. We monitored the number of consecutive observations of drooling and the portion of the pen exhibiting this sign to determine when these technologies should be supplemented. Studies have used this aspect of panting to describe excessive heat load in cattle (e.g., Gaughan and Mader, 2014; Schütz et al., 2014). For Mat, we added spray water and fans as described in Baseline. For Targeted Air, we added spray water on the same schedule as Optimized Baseline as the air continued to flow through the duct nozzles. The decision to use 2 different spray schedules for Mat and Optimized Baseline was made based on the predicted energy and water performance of these technologies. The Mat treatment was predicted to be highly energy efficient, so it could absorb the additional "penalty" of higher water use, whereas the assessment of Targeted Air would likely benefit from a more conservative use of water. At the time the experiment was conducted, we did not know whether the differences in spray schedule would matter or not because they had not been directly compared in other work.

A crossover design was used to test the effects of all 4 treatments (Baseline, Optimized Baseline, Targeted Air, and Mat) in all 8 groups of cows. Each pen was used to test 2 treatments: pen $\mathrm{M}$ operated the Mat and Optimized Baseline treatments, and pen $\mathrm{T}$ tested the Targeted Air and Baseline treatments. Each group of cows were housed together for $3 \mathrm{~d}$ before data collection. After the morning milking on d 3, each group switched pens to experience both environments for at least $24 \mathrm{~h}$ before data collection began. During the habituation, both pens received Baseline cooling. Following the habituation period, each treatment was applied 
Table 1. Program logic for the heat abatement strategies tested at the varied temperature thresholds and cooling supplementation

\begin{tabular}{|c|c|c|c|c|c|c|c|}
\hline Cooling strategy & $\begin{array}{l}\text { Outdoor air } \\
\text { temperature }\end{array}$ & \multicolumn{3}{|c|}{ Near lying area } & \multicolumn{3}{|c|}{ Near feed bunk } \\
\hline Baseline & $\geq 22.2^{\circ} \mathrm{C}$ & On & - & - & $\begin{array}{l}1.5 \text { min on } \\
6 \text { min off }\end{array}$ & - & - \\
\hline Optimized Baseline & $\geq 22.2^{\circ} \mathrm{C}$ & - & - & - & $\begin{array}{l}0.5 \text { min on } \\
4.5 \text { min off }\end{array}$ & On & - \\
\hline Mat & $\begin{array}{l}\geq 18.9^{\circ} \mathrm{C} \\
\geq 30^{\circ} \mathrm{C}\end{array}$ & $\overline{\mathrm{On}}$ & $\begin{array}{l}\text { On } \\
\text { On }\end{array}$ & - & $\begin{array}{l}1.5 \mathrm{~min} \text { on } \\
6 \mathrm{~min} \text { off }\end{array}$ & - & - \\
\hline
\end{tabular}

for $3 \mathrm{~d}$, totaling $12 \mathrm{~d}$ per cohort, because we find that the loggers used to collect BT (see details below) begin to result in adverse effects, namely discharge, if they are inserted for more than 2 wk. Observations occurred on all $12 \mathrm{~d}$ of treatment. All behavioral and physiological measurements began as soon as treatments were switched at $0400 \mathrm{~h}$ and continued for $3 \mathrm{~d}$ per treatment. Milk production was expected to have a lag of several hours, so to account for it, we began data collection for this parameter with the first afternoon milking on d 1 of each treatment. Finally, treatment order was balanced using random selection without replacement of unique permutations.

All 4 treatments were controlled by a programmable logic controller (EASY721-TC-DC, Eaton Moeller, Dublin, Ireland) and switches, as well as 2 DataTakers (DataTaker DT-85 in the freestall area and a DT-80 in the feed area, Thermo Fisher Scientific). The DataTaker collected and transmitted information to the programmable logic controller to turn on and off cooling equipment automatically based on AT (Table 1).

\section{Physiological Measures}

Respiration rates were recorded every $30 \mathrm{~min}$ from 1000 to $1900 \mathrm{~h}$, when cows were in their pens. We measured the time for 10 flank movements and converted it to breaths per minute to compare with other studies. Data were collected by 14 observers; interobserver reliability was calculated using regression analysis $\left(\mathrm{R}^{2}\right.$ $\geq 0.95$; intercept $=-0.17$ to $3.55, P \geq 0.07$; slope $=$ 0.95 to $1.03, P \geq 0.06$ ) based on 31 video clips that represented a range of $\mathrm{RR}$. Observers were not blind to treatment.

Body temperature was recorded intravaginally every 3 min 24 h/d using data loggers (DST centi-T, accuracy: $\pm 0.1^{\circ} \mathrm{C}$, resolution: $\pm 0.032^{\circ} \mathrm{C}$; Star-Oddi, Garðabær, Iceland) attached to a shortened, hormone-free con- trolled internal drug release insert (DEC International NZ Ltd., Hamilton, New Zealand).

\section{Behavioral Measures}

Cattle behavior was recorded continuously $24 \mathrm{~h} / \mathrm{d}$ with 12 video cameras (WV-BP334 black-and-white CCTV video cameras; Panasonic Corp. North America, Secaucus, NJ). Six cameras were placed 2.3 to $3.2 \mathrm{~m}$ above the floor at the feed bunk, 2 cameras were placed $2.7 \mathrm{~m}$ above the floor of the lying area, and 4 cameras were placed 2.6 to $2.9 \mathrm{~m}$ above the floor of the unshaded areas. All cameras were set to record at medium quality (15 frames/s), and were connected to a digital video recorder with surveillance software (GV Surveillance System version 8.4; GeoVision Inc., Taipei, Taiwan). Red string lights were used in the feed bunk area for nighttime visibility. Lying areas were illuminated with fluorescent lights $24 \mathrm{~h} / \mathrm{d}$, as per farm practice.

Individual cows were identified by their coat patterns and colored collars with reflective tape. Posture, location in the pen, and feeding behavior were recorded using instantaneous scan sampling every 3 min over 24-h periods beginning at $0400 \mathrm{~h}$. Posture was recorded as either lying, standing, or standing partially or fully in the freestall. Lying was defined as the flank or chest of the cow being in contact with the ground or bedding. Standing partially or fully in the freestall was defined as a cow having 2 or more hooves on the sand bedding or cement curb of a stall with the chest not in contact with the bedding. Location in the pen was mutually exclusive and could be recorded as within the head gate, feed bunk, shelter, or open area. Within the head gate was defined as a cow having her poll and at least 1 ear past the bars of the head gate (area A, Figure 1). The feed bunk area was defined as a cow having at least 1 hoof within $1.8 \mathrm{~m}$ of the head gates, which was designated by a black and white painted line on the 
ground, and her head not being through the gate (area B, Figure 1). A cow was recorded in the shelter area when at least 1 hoof was within the boundaries of the structure that covers the lying area. The open area was defined as a cow having all 4 hooves in the unshaded area of the pen between the shelter and painted line of the feed bunk area. When the poll was past the head gates, the cow was recorded to be feeding if her mouth was directed to the bottom of the bunk or if she was chewing visible feed. Video was watched for up to $20 \mathrm{~s}$ from the instantaneous scan time to determine if a cow was feeding. If a cow was not seen on video (i.e., left the pen for milking), she was listed as not visible. Data were recorded by 18 trained observers, and interobserver reliability was calculated using kappa coefficient for each measure ( $\kappa \geq 0.9$ for all behaviors). Reliability was based on 78 predetermined instantaneous scans of pilot data. Observers were not blind to treatment.

\section{Rumination}

Rumination was captured every minute for $24 \mathrm{~h} / \mathrm{d}$ by SCR HRLDn-tags (SCR Engineers Ltd., Netanya, Israel) on collars around the cows' neck. Data were extracted from the SCR tags using Heatime Pro (v.15.0.13.0) software as RTMessageLog files. The SCR collars collect information about a cow's behavior throughout 1 min and designate each minute to a behavior based on a predetermined hierarchy or what the majority of the minute was spent on. Rumination has the highest priority of behaviors. The collars were validated for specificity and sensitivity using video recordings. Both measures were above $90 \%$ for rumination behavior (A. V. Carrazco, UC Davis, CA; personal communication).

\section{Energy and Water Use}

Data loggers (Supplemental Table S1; https://doi .org/10.3168/jds.2019-17351) collected information about the energy and water used by each treatment. Using these data, we determined the average hourly consumption of energy and water per treatment on a kilowatt-hour or liter per cow basis. These calculations were conducted for the 2 scenarios in which each spray nozzle served either 2 or 3 cows. Water use was determined with Equation [1], where $Q_{\text {cow }}$ is L/cow, $n_{\text {nozzles,barn }}$ is the number of spray nozzles in the barn, $\dot{Q}_{\text {nozzle }}$ is the flow rate per nozzle, and $n_{\text {cows,barn }}$ is the number of cows in the barn. Electricity use per cow $\left(\mathrm{P}_{\text {cow }}\right)$ was determined using Equation [2], which calculates the sum of the fan and pump power required to pump water from a well to the spray nozzles. The fan power is determined from the number of fans in the barn $\left(n_{\text {fans,barn }}\right)$ and the power per fan $\left(\mathrm{P}_{\mathrm{fan}}\right)$. The pump power is the water flow rate for the spray nozzles multiplied by the sum of the static head and required water pressure $(240 \mathrm{kPa})$, where the static head is the mechanical energy required to pump water of density $1,000 \mathrm{~kg} / \mathrm{m}^{3}\left(\rho_{\text {water }}\right)$ from a 100-m-deep well against gravity (Perrone and Jasechko, 2017). The total hydraulic power required is divided by an assumed 50\% overall pump efficiency (Irrigation Training and Research Center, 2003):

$$
\begin{gathered}
Q_{\text {cow }}=\frac{n_{\text {nozzles,barn }} \times \dot{Q}_{\text {nozzle }}}{n_{\text {cows }, \text { barn }}}, \\
\mathrm{P}_{\text {cow }}=\frac{n_{\text {fans,barn }} \times \mathrm{P}_{\text {fan }}}{n_{\text {cows,barn }}} \\
+\frac{Q_{\text {cow }} \times\left(\rho_{\text {water }} \times \text { well depth } \times \text { gravity }+ \text { spray nozzle pressure }\right)}{\text { pump efficiency } \times n_{\text {cows,barn }}} .
\end{gathered}
$$

\section{Environmental Conditions}

A sensor (HMP110, Vaisala, Helsinki, Finland) mounted in pen $\mathrm{M}$ approximately $2.3 \mathrm{~m}$ above the stalls measured AT and relative humidity (RH) every minute. An additional measure of heat load was temperature-humidity index (THI), calculated using the following equation from Kelly and Bond (1971):

$$
\begin{aligned}
\mathrm{THI}=(1.8 \times & \mathrm{AT}+32)-[(0.55-0.0055 \times \mathrm{RH}) \\
& \times(1.8 \times \mathrm{AT}-26)] .
\end{aligned}
$$

\section{Data Management and Statistical Analysis}

Because of technology malfunctions, $3 \mathrm{~d}$ of data were excluded for the Mat treatment and $2 \mathrm{~d}$ for the Baseline from 2 groups (1 group/treatment). Milk yield was excluded for $1 \mathrm{~d}$ from 3 different cows in 2 groups due to missing data (1 d Optimized Baseline, 2 d Targeted Air). Rumination data are missing from 1 cow for all treatments due to SCR collar malfunction. Data from the Jersey cows were also excluded because we did not have an a priori question about breed differences, and the literature suggests they are more heat tolerant than Holsteins (Seath and Miller, 1947; Muller and Botha, 1998; Kadzere et al., 2002). The Holsteins had an average milk yield of $37.5 \pm 4.5 \mathrm{~kg} / \mathrm{d}$, DIM $203 \pm 73$, and parity $2 \pm 1$ lactations and were all pregnant for 105 $\pm 42 \mathrm{~d}$.

Data were analyzed using SAS 9.4 (SAS Institute, 2014). All data were evaluated for normality and homoscedasticity of variance by using residuals versus fits 
Table 2. Covariance structures and denominator degrees of freedom estimates used for the interaction between the response variables and either air temperature or temperature-humidity index ( $P$-value of that interaction also included)

\begin{tabular}{llll}
\hline Response variable & Covariance \\
structure $^{2}$ & $\begin{array}{c}\text { df treatment } \\
\times \text { weather }\end{array}$ & $\begin{array}{c}P \text {-value treatment } \\
\text { weather }\end{array}$ \\
\hline Air temperature & & & 76 \\
BT & VC & 76 & 0.47 \\
RR & AR(1) & 76 & 0.02 \\
Milk yield & CS & 72 & 0.15 \\
Time spent lying & VC & 72 & 0.08 \\
Time spent standing partially or fully in stall & VC & 72 & 0.26 \\
Time spent in feed bunk area & CS & 72 & 0.43 \\
Time spent feeding in feed bunk area & & 76 & 0.82 \\
Temperature-humidity index & VC & 76 & 0.57 \\
BT & AR(1) & 76 & 0.03 \\
RR & CS & 72 & 0.10 \\
Milk yield & VC & 72 & 0.12 \\
Time spent lying & VC & 72 & 0.27 \\
Time spent standing partially or fully in stall & VC & 72 & 0.64 \\
Time spent in feed bunk area & AR $(1)$ & 0.67 \\
Time spent feeding in feed bunk area & & & \\
\hline
\end{tabular}

${ }^{1} \mathrm{BT}=$ body temperature; $\mathrm{RR}=$ respiration rate.

${ }^{2} \mathrm{VC}=$ variance components; $\mathrm{AR}(1)=$ autoregressive; $\mathrm{CS}=$ compound symmetry.

plots and Q-Q plots. Treatment effects were evaluated for posture and location, rumination, RR, BT, and milk yield variables with group averages $(\mathrm{n}=8)$ in 2 ways. First, overall treatment differences using daily averages were compared (1 value per group in each treatment, an average of $3 \mathrm{~d}$ ). Second, hourly averages by treatment were used to look at time-dependent differences (1 value per group in each treatment, an average of that hour on $3 \mathrm{~d}$ ). Separate models were run for each hour. Mixed models (PROC MIXED) were used with all dependent variables. Variance components were used as the covariance structure for each model based on model fit, with fixed effect for treatment and random effect for group. Degrees of freedom (df) were estimated using the containment method $(\mathrm{df}$ test $=1$, df error $=19)$; PDIFF was used to make pairwise comparisons of each treatment to the Baseline for both types of models.

Similar models were used to evaluate treatment by weather (AT and THI; both treated as fixed terms) interactions for all measures using daily averages (3 values per group in each treatment). Covariance structure varied by model based on best fit (Akaike information criterion), with fixed effects for weather variable, treatment, and their interactions, and group was included as a random effect (Table 2). Degrees of freedom were estimated using the between-within method ( $\mathrm{df}$ test $=$ 1 , df error $=20$ ). All model structures were selected based on best fit. The method of estimating df was chosen to ensure that the correct error term was used, based on our experimental unit.

\section{RESULTS}

\section{Environmental Conditions}

Environmental conditions for $24 \mathrm{~h}$ and the RR observation period (1000-1900 h) are described in Table 3. Supplemental cooling was added to the Mat and Targeted Air treatments for an average of $34.8 \pm 10.1 \%$ of the 24 -h period and $79.6 \pm 19.0 \%$ of the time during RR observations (Figure 2a). No rainfall occurred during this period.

Table 3. Summary (averages of daily mean, minimum, and maximum) of weather conditions during $24 \mathrm{~h}$ and respiration rate (RR) observations (1000-1900 h)

\begin{tabular}{|c|c|c|c|c|c|c|}
\hline Weather variable & \multicolumn{3}{|c|}{$24 \mathrm{~h}$} & \multicolumn{3}{|c|}{$\mathrm{RR}$ period } \\
\hline Temperature-humidity index & $72.1 \pm 7.0$ & 71.3 & 73.0 & $79.0 \pm 3.2$ & 78.2 & 79.8 \\
\hline Relative humidity (\%) & $49.0 \pm 18.0$ & 46.8 & 51.3 & $33.0 \pm 10.0$ & 30.5 & 35.0 \\
\hline Time spent $<18.9^{\circ} \mathrm{C}(\% / \mathrm{d})$ & $19.0 \pm 11.6$ & - & - & $0.0 \pm 0.3$ & - & - \\
\hline Time spent at $18.9-22.1^{\circ} \mathrm{C}(\% / \mathrm{d})$ & $19.0 \pm 6.8$ & - & - & $0.1 \pm 0.6$ & - & - \\
\hline
\end{tabular}


- Baseline $\rightarrow$-Targeted Air -- Mat $\rightarrow$ Optimized Baseline $\cdots \cdot . \cdot$ Air Temperature $\left({ }^{\circ} \mathrm{C}\right)$

a)

b)

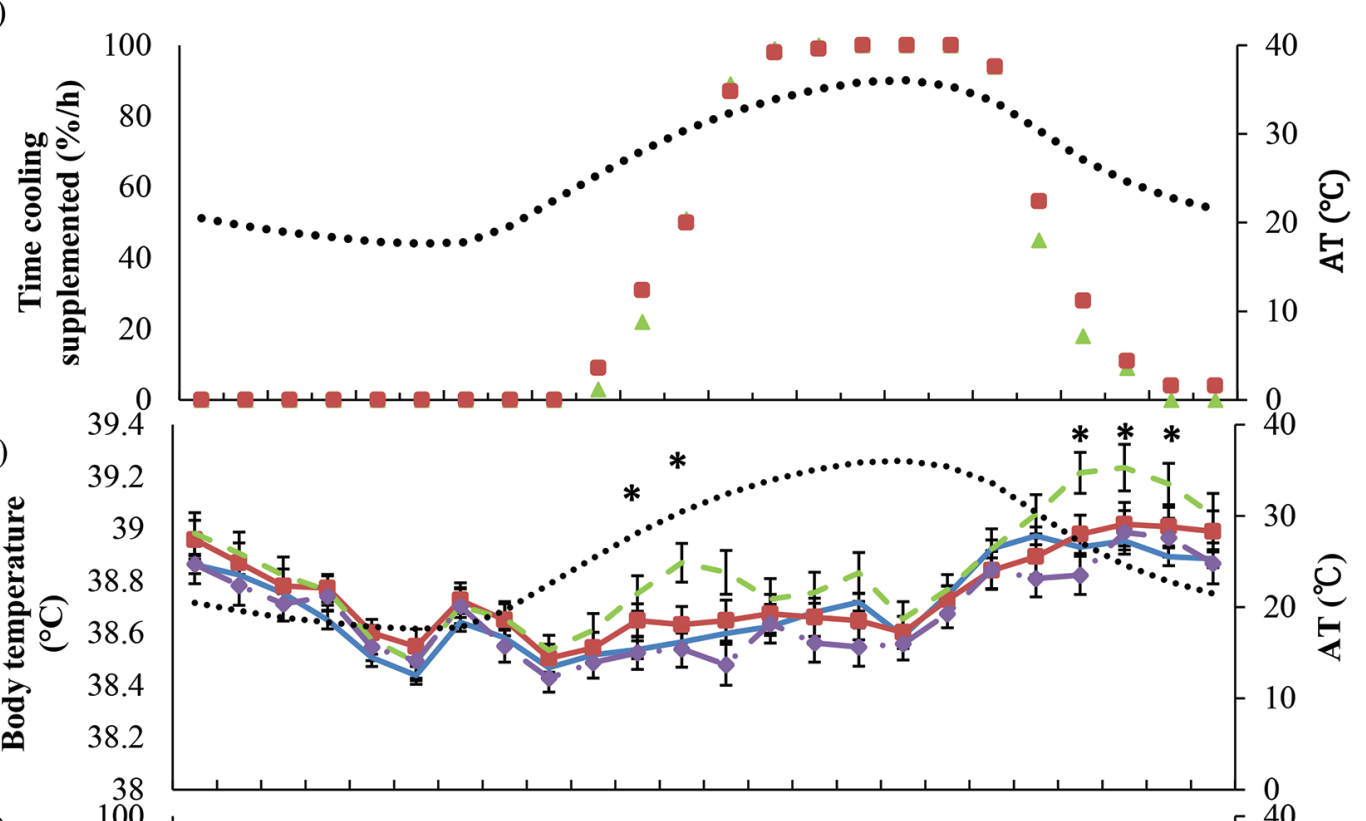

c)

d)
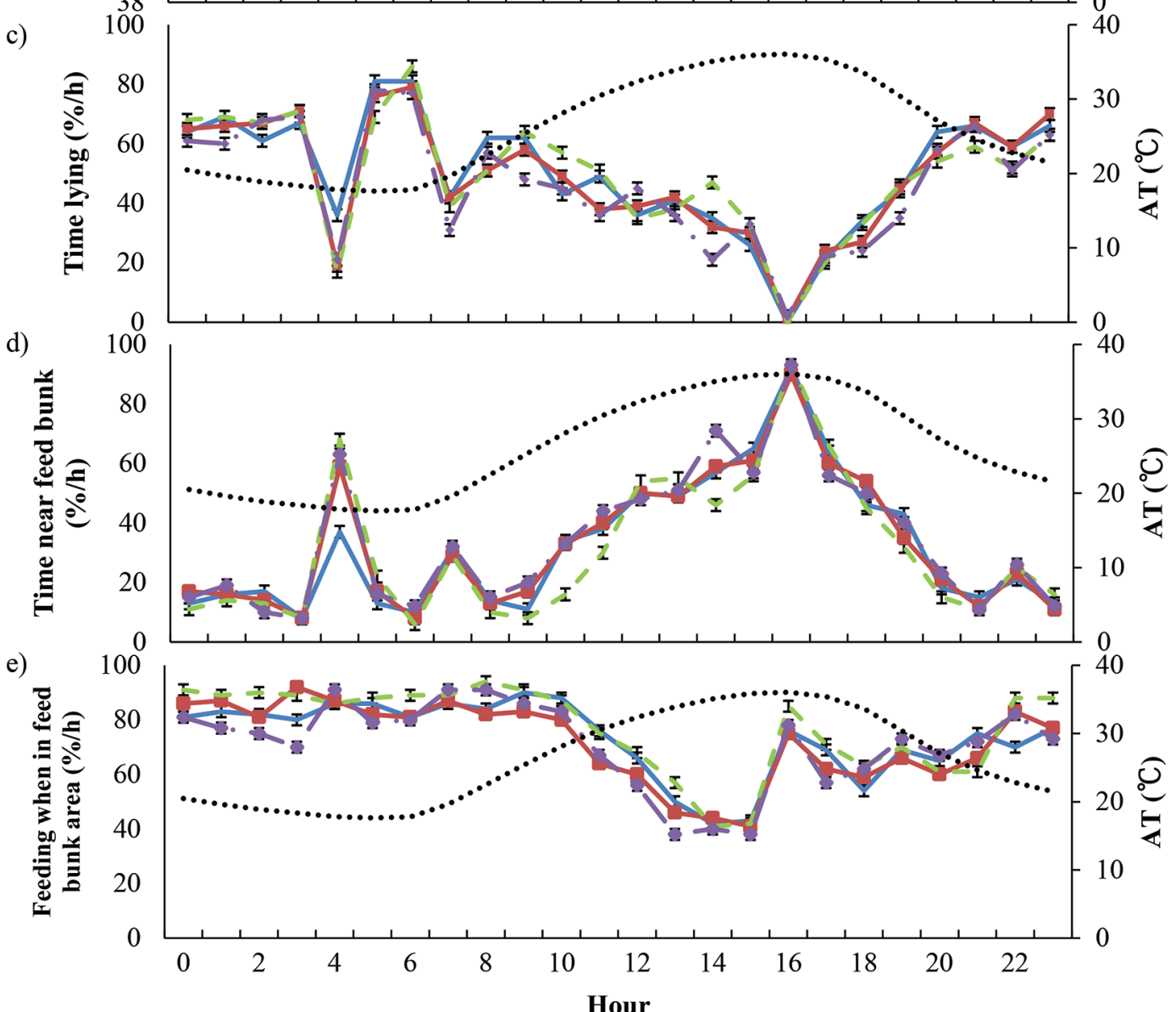

Figure 2. (a) The average amount of time $(\% / \mathrm{h})$ that supplemental cooling was added per treatment (Mat and Targeted Air). Least squares means \pm standard error of (b) body temperature, (c) time spent lying in the freestall beds, (d) time spent near the feed bunk (areas A + B), and (e) time spent feeding $(\% / \mathrm{h})$ when in the feed bunk area (areas A $+\mathrm{B})$ in response to heat abatement. Hourly mean air temperature (AT, $\left.{ }^{\circ} \mathrm{C}\right)$ is presented on the secondary axis with the dotted black line. ${ }^{*}$ Differences between Mat and Baseline are significant $(P<0.05)$. Cows were milked at approximately 0400 and $1600 \mathrm{~h}$ and fed at 0400, 1000, 1600, and $2200 \mathrm{~h}$. 
Table 4. Daily mean and standard error of the behavioral and physiological responses experienced by each heat abatement strategy

\begin{tabular}{|c|c|c|}
\hline Physiological or behavioral response & Treatment & Daily mean $\pm \mathrm{SE}$ \\
\hline \multirow[t]{4}{*}{ Respiration rate (breaths/min) } & Baseline & $59 \pm 3$ \\
\hline & Optimized Baseline & $60 \pm 3$ \\
\hline & Targeted Air & $59 \pm 3$ \\
\hline & Mat & $65 \pm 3$ \\
\hline \multirow[t]{4}{*}{ Body temperature $\left({ }^{\circ} \mathrm{C}\right)$} & Baseline & $38.7 \pm 0.05$ \\
\hline & Optimized Baseline & $38.7 \pm 0.05$ \\
\hline & Targeted Air & $38.8 \pm 0.05$ \\
\hline & Mat & $38.8 \pm 0.05$ \\
\hline \multirow[t]{4}{*}{ Milk yield $(\mathrm{kg} / \mathrm{d})$} & Baseline & $40 \pm 2$ \\
\hline & Optimized Baseline & $38 \pm 2$ \\
\hline & Targeted Air & $39 \pm 2$ \\
\hline & Mat & $38 \pm 2$ \\
\hline \multirow[t]{4}{*}{ Lying (\%/d) } & Baseline & $53 \pm 2$ \\
\hline & Optimized Baseline & $48 \pm 2$ \\
\hline & Targeted Air & $52 \pm 2$ \\
\hline & Mat & $52 \pm 2$ \\
\hline \multirow[t]{4}{*}{ Standing partially or fully in stall $(\% / d)$} & Baseline & $4 \pm 1$ \\
\hline & Optimized Baseline & $4 \pm 1$ \\
\hline & Targeted Air & $4 \pm 1$ \\
\hline & Mat & $4 \pm 1$ \\
\hline \multirow[t]{4}{*}{ Standing in feed bunk area (\%/d) } & Baseline & $32 \pm 2$ \\
\hline & Optimized Baseline & $35 \pm 2$ \\
\hline & Targeted Air & $34 \pm 2$ \\
\hline & Mat & $31 \pm 2$ \\
\hline \multirow{4}{*}{ Feeding while in feed bunk area $(\% / d)$} & Baseline & $70 \pm 2$ \\
\hline & Optimized Baseline & $69 \pm 2$ \\
\hline & Targeted Air & $69 \pm 2$ \\
\hline & Mat & $75 \pm 3$ \\
\hline
\end{tabular}

\section{Physiological and Behavioral Responses to Heat Load}

RR, BT, and Milk Production. Compared with Baseline, treatment had no effect on daily average RR $(P>0.90)$. Respiration rate averaged $61 \pm 3$ breaths/ min across treatments (Table 4 ). On an hourly basis, $\mathrm{RR}$ was significantly higher for the Mat treatment than for Baseline at h 10 and 11 (70 vs. 58-59 \pm 3 breaths/ $\min ; P<0.03)$.

Average BT was $38.7 \pm 0.05^{\circ} \mathrm{C}$ across treatments (Table 4), and BT average per treatment tended to be higher for the Mat treatment than for Baseline $(P=$ 0.09). This tendency was reflected by higher hourly BT at $\mathrm{h} 10,11,21,22$, and 23 with a difference of 0.2 to $0.3^{\circ} \mathrm{C}\left(38.5-38.9\right.$ vs. $38.7-39.2 \pm 0.06-0.09^{\circ} \mathrm{C} ; P<0.04$, Figure 2b).

Milk yield averaged $39 \pm 2 \mathrm{~kg} / \mathrm{d}$ and did not differ for any treatment compared with Baseline $(P>0.50$, Table 4).

Lying and Standing Behaviors, Use of Feed Bunk Areas, and Feeding and Rumination Activity. Cows were observed lying down, on average 51.2 $\pm 2 \% / \mathrm{d}$, which was similar regardless of treatment $(P$ $>0.14$; Table 4). Average lying time was similar for the Mat treatment and Baseline $(56.5 \pm 5 \% / \mathrm{h}, 56.6 \pm$
$6 \% / \mathrm{h}$ respectively) throughout the day but also during h $10,11,21,22$, and $23(P>0.10)$.

Regardless of the treatment, cows spent $3.9 \pm 0.5 \% / \mathrm{d}$ standing with 2 or more hooves in the sand freestalls $(P$ $>0.87$; Table 4 ).

For all 4 treatments, time spent using the feed bunk area (areas $\mathrm{A}+\mathrm{B})$ did not differ $(P>0.87)$. Cows spent on average $32.9 \pm 1.6 \% / \mathrm{d}$ within these 2 areas (Table 4).

Of the time cows were within the feed bunk area (areas $\mathrm{A}+\mathrm{B}$ ), they were feeding $70.8 \pm 2.4 \%$ of the time on average, regardless of treatment $(P>0.27$; Table 4$)$. Throughout the day, time spent feeding ranged from 37.6 to $93.9 \% / \mathrm{h}$ (Figure 2e). Time spent ruminating did not differ by treatment. The average percentage of time was $38.6 \pm 0.9 \% / \mathrm{d}$ and ranged from 18 to $54 \% / \mathrm{h}$.

\section{Weather Effects}

Treatment and weather interactions are shown by variable in Table 2. No interaction was found between treatment with AT or THI for BT, milk yield, standing with 2 or more hooves in the bed, time spent near the feed bunk, or time spent feeding while in this area across treatments $(P>0.10)$. For time spent lying, AT and treatment tended to interact $(P=0.08)$. Lying 
time in the Mat treatment did not decrease as much at higher AT as it did in the other treatments. Both AT and THI had a treatment interaction with $\mathrm{RR}(P<$ 0.03; Figure 3) as a more marked increase in $\mathrm{RR}$ was found for the Mat treatment.

\section{Water and Energy Use}

Water and energy use results are descriptive and are presented by average hourly consumption per cow based on the temperature thresholds and by the num- ber of cows the spray nozzle would serve (Table 5). The water and energy used in our study varied by treatment, with the order of efficiency varying based on the temperature threshold. Below $30^{\circ} \mathrm{C}$, the Mat treatment was the most efficient in terms of water and energy use, whereas Baseline used the greatest amount of water and Targeted air used the most energy. At or above $30^{\circ} \mathrm{C}$, the Optimized Baseline treatment was the most efficient with water and energy use, while Mat used the most water and Targeted Air used the most energy.
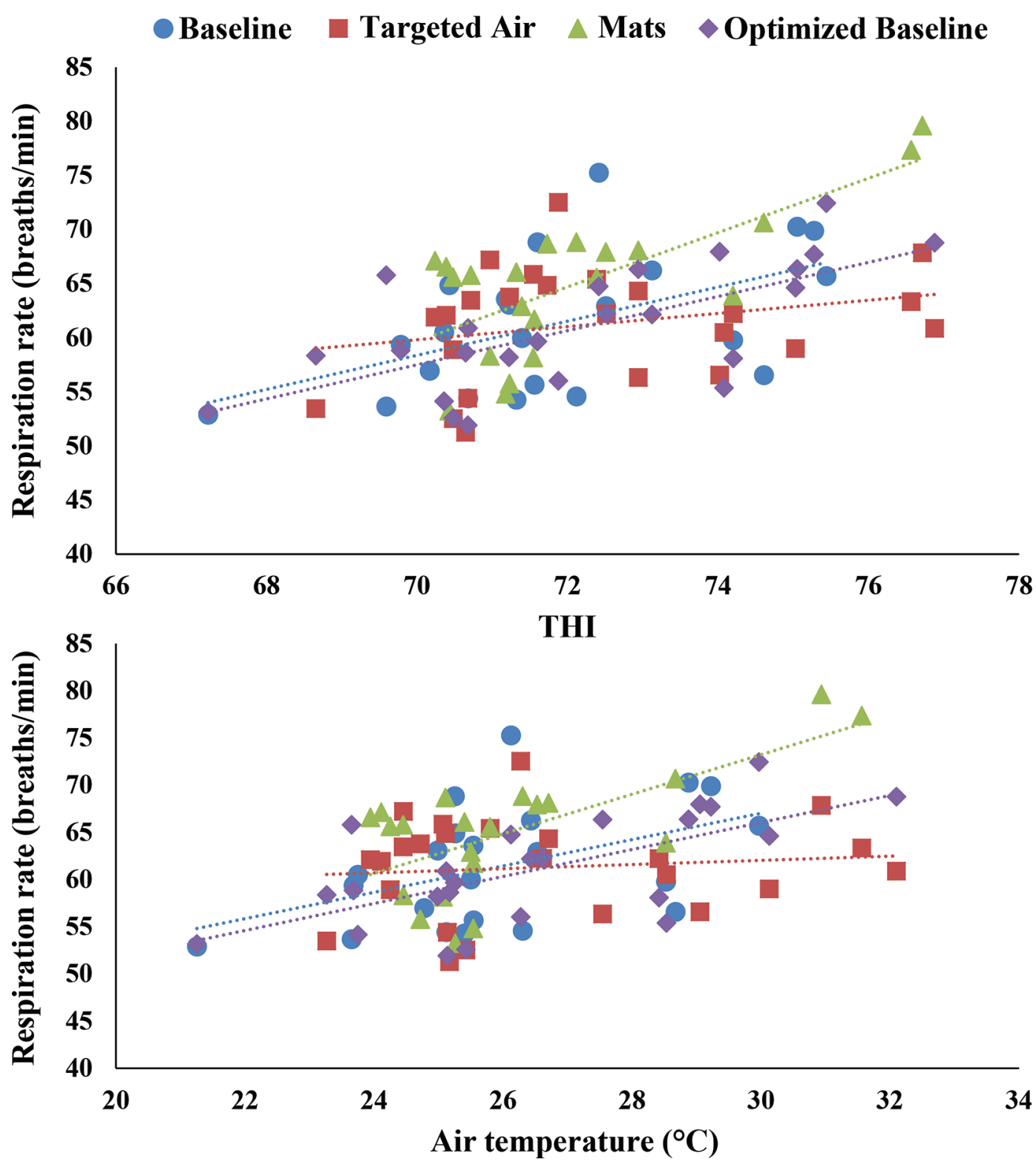

Figure 3. Respiration rate (breaths/min) response to temperature-humidity index (THI) and air temperature. A significant interaction occurred between THI and air temperature with respiration rate across treatments. 


\section{DISCUSSION}

In this study, differences in heat load by treatment were only apparent in the late morning and evening. Both $\mathrm{RR}$ and $\mathrm{BT}$ were higher than the Baseline treatment when cows were in the Mat treatment during the hours that additional cooling was not provided, which had been added above $30^{\circ} \mathrm{C}$ for ethical reasons. This finding indicates that the conductive cooling mats below the sand freestalls alone were not sufficient. We saw similar physiological and behavioral responses in the Baseline, Optimized Baseline, and Targeted Air treatments. Milk yield did not differ, likely because relatively low levels of heat load were experienced in all treatments. We saw no overall differences in behavior, and each heat abatement strategy was used by the cows. Energy and water use varied by treatment and could continue to be improved for the future. Taken together, these results indicate that the Optimized Baseline treatment was the most efficient heat abatement option while maintaining cow cooling effectiveness.

\section{Effects of Heat Abatement on Physiological Responses}

The hourly differences seen in the Mat treatment are a conservative indicator that this method of heat abatement does not cool cows as well as spray water and fans. Cows experienced higher RR, by 11 to 12 breaths/ min, and a BT elevated by 0.2 to $0.3^{\circ} \mathrm{C}$ on the Mat treatment compared with Baseline in the late morning when at times, supplemental cooling was just beginning to be activated and turned off in the evening, indicating a higher heat load (West, 2003; Correa-Calderon et al., 2004). This outcome indicates that the Mat treatment without supplemental cooling is insufficient. We likely would have seen higher RR and BT had supplemental cooling not been provided during this treatment. In- deed, an interaction occurred between weather and RR As it became warmer, cows on the Mat treatment had higher RR than those in Baseline, likely due to the heat build-up that occurred before the addition of spray water and fans. An interaction between treatment, RR, AT, and THI was also observed by Chen et al. (2015).

Overall, the cows in our study were relatively cool, as indicated by the average $\mathrm{RR}$ and $\mathrm{BT}$ values observed and the lack of differences in milk yield. The $\mathrm{RR}$ treatment averages of 59 to 65 breaths/min were comparable to the lower values found on California farms (Tresoldi et al., 2017). The higher hourly averages of 70 breaths/min for Mat were comparable to those observed by Perano et al. (2015): 68 breaths/min in cows conductively cooled with $10^{\circ} \mathrm{C}$ water. Uncooled or shade-only controls have exhibited $\mathrm{RR}$ ranging from 95 to 115 breaths/min (Collier et al., 1981; Strickland et al., 1989; Brouk et al., 2003a); hence, our cows were relatively cool. Additionally, the mean $\mathrm{BT}$ of $38.7^{\circ} \mathrm{C}$ in our study was comparable to those observed by Tresoldi et al. (2018b) and lower than the uncooled control of $>39.1^{\circ} \mathrm{C}$ in Chen et al. (2013). Cows that experience high levels of heat stress often show a decrease in milk yield (West et al., 2003). No change in this physiological response occurred during our study, compared with the almost $5 \mathrm{~kg} / \mathrm{d}$ decrease exhibited by uncooled cattle in Kendall et al. (2007), which offers further evidence of the relatively low levels of heat load in our cows.

\section{Effects of Heat Abatement on Behavioral Response}

Cows spent an average of $12.3 \mathrm{~h} / \mathrm{d}$ lying, which is comparable to the $12.5 \mathrm{~h} / \mathrm{d}$ observed from previous work conducted by our team (e.g., Chen et al., 2016; Tresoldi et al., 2019). As heat load increases, cows spend less time lying down (Cook et al., 2007; Schütz et al., 2010; Chen et al., 2016), which would prevent conductive cooling via the freestall surface.

Table 5. Water and energy average hourly consumption observed on a per cow basis at the lower and upper heat abatement thresholds ${ }^{1}$

\begin{tabular}{|c|c|c|c|c|c|c|c|c|}
\hline \multirow{2}{*}{ Treatment $^{2}$} & \multicolumn{4}{|c|}{ Electricity use (kWh/cow) } & \multicolumn{4}{|c|}{ Water use (L/cow) } \\
\hline & \multicolumn{2}{|c|}{2 cows $/$ nozzle } & \multicolumn{2}{|c|}{3 cows $/$ nozzle } & \multicolumn{2}{|c|}{2 cows/nozzle } & \multicolumn{2}{|c|}{3 cows/nozzle } \\
\hline Baseline & 0.06 & 0.06 & 0.05 & 0.05 & 27.3 & 27.3 & 18.2 & 18.2 \\
\hline Optimized Baseline & 0.05 & 0.05 & 0.04 & 0.04 & 13.6 & 13.6 & 9.1 & 9.1 \\
\hline Targeted Air & 0.16 & 0.17 & 0.16 & 0.17 & 3.8 & 17.4 & 3.8 & 12.9 \\
\hline
\end{tabular}

${ }^{1}$ Calculations were made for each heat abatement strategy under the assumption that a spray nozzle would serve either 2 or 3 cows each. We also assumed that water would be pumped from a $100-\mathrm{m}$ well with an overall pump efficiency of $50 \%$.

${ }^{2}$ At the upper temperature threshold $\left(\geq 30^{\circ} \mathrm{C}\right)$, additional cooling was added to the Targeted Air and Mat treatments for ethical reasons.

${ }^{3}$ Mat values for water and energy use begin at a threshold of $\geq 18.9^{\circ} \mathrm{C}$. 
The conductive heat loss for the Mat treatment was not effective despite cows lying in the freestalls for similar amounts of time as in the Baseline. This lack of effectiveness could be due to the conductive cooling properties already exhibited by sand; Ortiz et al. (2015) showed this bedding type promoted the most heat exchange. Our Mat treatment may not have provided enough of an additional temperature gradient to allow for adequate heat transfer from the cows. Although our Mat treatment shows promise as an energy and water efficient cooling method for other applications, we do not see it as a particularly viable solution in practice. Cows spend less time lying down as heat load increases (e.g., Cook et al., 2007; Schütz et al., 2010; Chen et al., 2016), suggesting that cow behavioral responses to warm weather may also limit the potential for this form of heat abatement.

Use of the feed bunk area and time spent feeding did not differ between treatments. The amount of time spent near the feed bunk averaged about $7.7 \mathrm{~h} / \mathrm{d}$ and, of that time, approximately $5.4 \mathrm{~h} / \mathrm{d}$ was spent feeding. The time spent near the feed bunk was comparable to the $7.8 \mathrm{~h} / \mathrm{d}$ observed by Chen et al. (2013). However, it was greater than the 5.2 to $5.8 \mathrm{~h} / \mathrm{d}$ observed in other studies (DeVries et al., 2003; Tucker et al., 2006; Tresoldi et al., 2019). These differences may be a result of climate conditions or the amount of time heat abatement was offered at the feed bunk. Chen et al. (2013) offered spray water $24 \mathrm{~h} / \mathrm{d}$, and Tresoldi et al. (2019) offered spray water on a fixed schedule from 0815 to $2330 \mathrm{~h}$. Heat abatement in our study was triggered by AT, which did not always drop below the threshold at night (Table 3). For example, the mean amount of time the spray water was triggered by AT was $\sim 15 \mathrm{~h} / \mathrm{d}$ but ranged from about 4 to $24 \mathrm{~h} / \mathrm{d}$. Additionally, cows in our study seemed to use the feed bunk area for cooling in the afternoon, as described in other studies (Chen et al., 2013; Tresoldi et al., 2019). These studies show that when cows are in the feed bunk area in the afternoon, time feeding decreases from $\sim 90 \% / \mathrm{h}$ in the morning to 50 to $80 \% / \mathrm{h}$ in the afternoon. Our study showed similar results because the time cows spend feeding when at the feed bunk was $\sim 90 \% / \mathrm{h}$ early in the morning and 40 to $70 \% / \mathrm{h}$ in the afternoon (Figure $2 \mathrm{~d}$ and $2 \mathrm{e}$ ). Cows may be using this area for cooling from the spray water, rather than eating during warmer times of the day.

Cows in our study spent an average of $5.4 \mathrm{~h} / \mathrm{d}$ feeding and $9.3 \mathrm{~h} / \mathrm{d}$ ruminating, creating a combined time budget of $14.7 \mathrm{~h} / \mathrm{d}$ for both. Although cows in our study were feeding more than the average of $4.7 \mathrm{~h} / \mathrm{d}$ reviewed by Beauchemin (2018), the combined time spent feeding and ruminating is within the $\sim 16 \mathrm{~h} / \mathrm{d}$ maximum described in the same review. This further supports the lower heat load our cows experienced across treat- ments, as Abeni and Galli (2017) showed heat stress can reduce rumination by $35 \%$.

\section{Water and Energy Use Variation by Heat Abatement}

Both water and energy have been identified in the literature as areas of economic concern for the dairy industry (St-Pierre et al., 2003; Collier et al., 2006; von Keyserlingk et al., 2013). However, there is little consistency across the literature in how these values are reported or even if they are described at all.

For our 4 treatments, the water and energy efficiency were dependent on AT. We added supplemental cooling to the convective and conductive strategies at $\geq 30^{\circ} \mathrm{C}$ for ethical reasons, but this addition also resulted in greater water and energy use. Below $30^{\circ} \mathrm{C}$, the Mat treatment was most efficient due to the SWEC's energy-conscious design and the ability to recirculate water. The Targeted Air treatment was the second-most efficient for water but was consistently the highest in energy use. This result is likely due to using 2 evaporative coolers (for cooling in the freestall and feed areas) and their inefficiency in terms of power consumed per unit of airflow delivered; we expect that higher efficiencies could be achieved in a larger-scale implementation with higher efficiency fans and pumps. Above $30^{\circ} \mathrm{C}$, the Mat and Targeted Air treatments used the most energy, and the Mat treatment was the least efficient for water use because it was supplemented with a larger quantity of spray water.

At both ambient thresholds, the Optimized Baseline was more efficient than the Baseline and a promising alternative. Below $30^{\circ} \mathrm{C}$, the Optimized Baseline used only an additional $0.02 \mathrm{~kW} / \mathrm{cow}$ each hour compared with the energy-efficient Mat treatment and half the water of the Baseline treatment. At or above $30^{\circ} \mathrm{C}$, the Optimized Baseline became the most efficient for both electricity and water, due to the reduced spray cycle of $0.5 \mathrm{~min}$ on/4.5 min off compared with Baseline (1.5 min on $/ 6$ min off). In comparison, the Mat treatment used water and energy to recirculate water in the mats and operate the SWEC, as well as the resources of the less efficient Baseline for the additional cooling. At this threshold, the Target Air treatment also had added water use of the more efficient Optimized Baseline and energy to pump spray water. Taken together, the Optimized Baseline is a more efficient option.

Placing our energy and water use results in the context of the broader literature is challenging. Previously, energy use of heat abatement on dairies has not been well described. von Keyserlingk et al. (2013) described total energy use and these values varied greatly, with dairies across the United States using between 300 to $1,500 \mathrm{kWh} /$ cow per year. Nearly $50 \%$ of this energy 
use is expected to come from the milking parlor (von Keyserlingk et al., 2013), and heat abatement alone has only been described by a few authors. Of those, Ortiz et al. (2015) reported that energy use of heat abatement can range from 0.71 to $1.76 \mathrm{~kW} / \mathrm{h}$ based on economic modeling from St-Pierre et al. (2003). It is not clear if this estimate is broken down to a per cow basis, as our study showed an hourly energy use range of far less, 0.03 to $0.17 \mathrm{kWh} /$ cow.

For water use, the key challenges in comparing our results to others include how values are reported and the type of heat abatement used. Some studies report water use on a seasonal basis, such as Perano et al. (2015) at 3,650 L/cow per season. Others, such as Harner et al. (2013), report using 56 to $75 \mathrm{~L} /$ cow per day for heat abatement. Our 4 heat abatement methods ranged in average hourly water use from 1.3 to $28.5 \mathrm{~L} /$ cow. The type of heat abatement can play a large role in the efficiency of water use. Bastian et al. (2003) evaluated conductive heat transfer from cows to waterbeds that were filled with $60.6 \mathrm{~L}$ of continuously cooled water, but they did not describe the regularity at which this consumption would occur nor how the water was actually cooled. Our Targeted Air treatment evaporative coolers used $3.8 \mathrm{~L} /$ cow per hour, which is within the range of 1.75 to $4.5 \mathrm{~L} /$ cow per hour required by the "cooling evaporation system" used by Frazzi et al. (2002). With further research, our Targeted Air treatment could prove more efficient if only 1 evaporative cooler was used.

Challenges also exist within a given type of heat abatement. For example, spray water has several factors that influence efficiency, such as flow rate, spray duration, spray frequency, and the number of cows/ spray nozzle. Although not well described, a few studies have considered cows/nozzle and suggest assuming that each nozzle can serve 3 cows (Chen et al., 2015; Tresoldi et al., 2017, 2018b). As seen in our study, the number of cows per spray nozzle can influence the amount of water needed on a dairy. Water use can also vary by spray cycle, as reported by Tresoldi et al. (2018b). They compared spray timing that resulted in water use of 19.6 and $33.6 \mathrm{~L} /$ cow per hour. In comparison, our spray strategies used water at a rate of 9.1 and 18.2 L/cow per hour, with the assumption of 3 cows/ nozzle. Both studies resulted an average BT of $38.7^{\circ} \mathrm{C}$, indicating that lower quantities of water can keep cows equally cool.

Future studies should incorporate the amount of energy that their heat abatement uses, particularly on the basis of hourly use of kilowatts per cow. Future studies looking at water use should also include flow rate, spray cycle, number of cows per spray nozzle, and other helpful factors to allow for calculation, or con- sider presenting the data based on liters per cow per hour. Supplemental Table S2 (https://doi.org/10.3168/ jds.2019-17351) presents all data that would be useful to report in future studies. Reporting energy and water use on a consistent basis of cow per hour will allow for easier translation and improved decision-making regarding heat abatement based on efficiency. As utility costs are expected to continue to rise and water availability is expected to decrease, efficiency of heat abatement should be prioritized.

\section{CONCLUSIONS}

Although the conductive cooling Mat treatment was energy and water efficient, it was not an effective heat abatement strategy. The evaporatively cooled Targeted Air and Optimized Baseline treatments kept cows equally as cool as the Baseline treatment but varied in their water and energy efficiency. Optimized Baseline is an effective heat abatement option that reduced water and energy use.

\section{ACKNOWLEDGMENTS}

We are grateful to those who assisted with data collection: Alex Chapman, Candy Lin, Lysi Newman, Fatima Sanchez, Mia Cotero, Kareen Mendoza, Berenice Garcia Oseguera, Bailey Westin, Lauren Maas, Adolfo Porras Madrigal, Elodie Fabre, Marion Coste, Leo Roche, Logan Chase, Lauren Taylor, Cindy Chen, Sherry Chen, Allie Essary, and Melissa Thurston, all of whom were affiliated with UC Davis at the time of the study. Many thanks also to Doug Gisi, Maria Patino, and the staff and interns of the UC Davis Dairy Teaching and Research Facility. We are grateful to Daniel Sehnert, Frank Sauers, Jose Villasenor, Blair Downey, and Sarah Adcock (all affiliated with UC Davis at the time of the study). We gratefully acknowledge the financial support of the California Energy Commission (EPC-16-010) and the infrastructure support of the Department of Animal Science and the College of Agricultural and Environmental Sciences of UC Davis. The authors have not stated any conflicts of interest.

\section{REFERENCES}

Abeni, F., and A. Galli. 2017. Monitoring cow activity and rumination time for an early detection of heat stress in dairy cow. Int. J. Biometeorol. 61:417-425. https://doi.org/10.1007/s00484-016-1222-z.

Bastian, K. R., K. G. Gebremedhin, and N. R. Scott. 2003. A finite difference model to determine conduction heat loss to a waterfilled mattress for dairy cows. Trans. ASAE 46:773-780. https:// doi.org/10.13031/2013.13592.

Beauchemin, K. A. 2018. Invited review: Current perspectives on eating and rumination activity in dairy cows. J. Dairy Sci. 101:47624784. https://doi.org/10.3168/jds.2017-13706. 
Brouk, M. J., J. P. Harner, J. F. Smith, A. K. Hammond, W. F. Miller, and A. F. Park. 2003a. Effect of soaking and misting on respiration rate, body surface temperature and body temperature of heat stressed dairy cattle. Pages $12-16$ in Proc. Kansas Dairy Day. Kansas State University, Manhattan.

Brouk, M. J., J. F. Smith, and J. P. Harner. 2003b. Effect of sprinkling frequency and airflow on respiration rate, skin temperature and body temperature of heat stressed dairy cattle. Pages 263-268 in Proc. 5th Int. Dairy Housing. Am. Soc. Agric. Eng., St. Joseph, MI, Fort Worth, TX.

Chen, J. M., K. E. Schütz, and C. B. Tucker. 2013. Dairy cows use and prefer feed bunks fitted with sprinklers. J. Dairy Sci. 96:50355045. https://doi.org/10.3168/jds.2012-6282.

Chen, J. M., K. E. Schütz, and C. B. Tucker. 2015. Cooling cows efficiently with sprinklers: Physiological responses to water spray. J. Dairy Sci. 98:6925-6938. https://doi.org/10.3168/jds.2015-9434.

Chen, J. M., K. E. Schütz, and C. B. Tucker. 2016. Cooling cows efficiently with water spray: Behavioral, physiological, and production responses to sprinklers at the feed bunk. J. Dairy Sci. 99:4607-4618. https://doi.org/10.3168/jds.2015-10714.

Collier, R. J., G. E. Dahl, and M. J. VanBaale. 2006. Major advances associated with environmental effects on dairy cattle. J. Dairy Sci. 89:1244-1253. https://doi.org/10.3168/jds.S0022-0302(06)72193 -2 .

Collier, R. J., R. M. Eley, A. K. Sharma, R. M. Pereira, and D. E. Buffington. 1981. Shade management in subtropical environment for milk yield and composition in Holstein and Jersey cows. J. Dairy Sci. 64:844-849. https://doi.org/10.3168/jds.S0022-0302(81)82656 -2 .

Cook, N. B., R. L. Mentink, T. B. Bennett, and K. Burgi. 2007. The effect of heat stress and lameness on time budgets of lactating dairy cows. J. Dairy Sci. 90:1674-1682. https://doi.org/10.3168/ jds.2006-634.

Correa-Calderon, A., D. Armstrong, D. Ray, S. DeNise, M. Enns, and C. Howison. 2004. Thermoregulatory responses of Holstein and Brown Swiss heat-stressed dairy cows to two different cooling systems. Int. J. Biometeorol. 48:142-148. https://doi.org/10.1007/ s00484-003-0194-y.

DeVries, T. J., M. A. G. von Keyserlingk, D. M. Weary, and K. A. Beauchemin. 2003. Measuring the feeding behavior of lactating dairy cows in early to peak lactation. J. Dairy Sci. 86:3354-3361. https://doi.org/10.3168/jds.S0022-0302(03)73938-1.

Esmay, M. L. 1969. Principles of Animal Environment. The AVI Publishing Company Inc., Westport, CT.

Flamenbaum, I., D. Wolfenson, M. Mamen, and A. Berman. 1986. Cooling dairy cattle by a combination of sprinkling and forced ventilation and its implementation in the shelter system. J. Dairy Sci. 69:3140-3147. https://doi.org/10.3168/jds.S0022-0302(86)80778 $-0$.

Frazzi, E., L. Calamari, and F. Calegari. 2002. Productive response of dairy cows to different barn cooling systems. Trans. ASAE 45:395405. https://doi.org/10.13031/2013.8520.

Gaughan, J. B., and T. L. Mader. 2014. Body temperature and respiratory dynamics in un-shaded beef cattle. Int. J. Biometeorol. 58:1443-1450. https://doi.org/10.1007/s00484-013-0746-8.

Hahn, L. G., J. D. Sikes, M. D. Shanklin, and H. D. Johnson. 1969 Dairy cow responses to summer air-conditioning as evaluated by switchback experimental design. Trans. ASAE 12:0202-0204. https://doi.org/10.13031/2013.38798.

Harner, J. P., M. J. Brouk, J. Potts, B. Bradford, and J. F. Smith. 2013. Scientific data for developing water budgets on a dairy. Pages 90-104 in Proc. West. Dairy Management Conf., Reno, NV.

Irrigation Training and Research Center. 2003. California Agricultural Water Electrical Energy Requirements. Attachment D. Accessed Nov. 22, 2019. http://agwaterstewards.org/wp-content/uploads/ 2016/08/EnergyReqs.PDF.

Kadzere, C. T., M. R. Murphy, N. Silanikove, and E. Maltz. 2002. Heat stress in lactating dairy cows: A review. Livest. Prod. Sci. 77:59-91. https://doi.org/10.1016/S0301-6226(01)00330-X.
Kelly, C. F., and T. E. Bond. 1971. Bioclimatic factors and their measurement. Page 77 in A Guide to Environmental Research on Animals. National Academies Press, Washington, DC.

Kendall, P. E., G. A. Verkerk, J. R. Webster, and C. B. Tucker. 2007. Sprinklers and shade cool cows and reduce insect-avoidance behavior in pasture-based dairy systems. J. Dairy Sci. 90:3671-3680. https://doi.org/10.3168/jds.2006-766.

Kester, E., M. Holzhauer, and K. Frankena. 2014. A descriptive review of the prevalence and risk factors of hock lesions in dairy cows. Vet. J. 202:222-228. https://doi.org/10.1016/j.tvjl.2014.07.004.

Muller, C. J. C., and J. A. Botha. 1998. The comparative performance of primiparous Holstein Friesland and Jersey cows on complete diets during summer in a temperate climate. S. Afr. J. Anim. Sci. $28: 161-166$

Ortiz, X. A., J. F. Smith, F. Rojano, C. Y. Choi, J. Bruer, T. Steele, N. Schuring, J. Allen, and R. J. Collier. 2015. Evaluation of conductive cooling of lactating dairy cows under controlled environmental conditions. J. Dairy Sci. 98:1759-1771. https://doi.org/10 $.3168 /$ jds.2014-8583.

Perano, K. M., J. G. Usack, L. T. Angenent, and K. G. Gebremedhin. 2015. Production and physiological responses of heat stressed lactating dairy cattle to conductive cooling. J. Dairy Sci. 98:52525261. http://dx.doi.org/10.3168/jds.2014-8784.

Perrone, D., and S. Jasechko. 2017. Dry groundwater wells in the western United States. Environ. Res. Lett. 12:104002. https://doi.org/ 10.1088/1748-9326/aa8ac0.

Ravagnolo, O., I. Misztal, and G. Hoogenboom. 2000. Genetic component of heat stress in dairy cattle, development of heat index function. J. Dairy Sci. 83:2120-2125. https://doi.org/10.3168/jds .S0022-0302(00)75094-6.

Rosenstock, T., S. Smukler, and T. Cavagnaro. 2006. California agricultural landscapes and climate change. Pages 3-12 in Climate Change: Challenges and Solutions for California Agricultural Landscapes. T. Cavagnaro, L. Jackson, and K. Scow, ed. California Climate Change Center, Sacramento, CA.

SAS Institute. 2014. SAS/STAT 9.4 User's Guide. SAS Institute Inc., Cary, NC.

Schmidt-Nielsen, K. 1964. Desert Animals. Physiological Problems of Heat and Water. Clarendon Press, Oxford, UK.

Schütz, K. E., N. R. Cox, and C. B. Tucker. 2014. A field study of the behavioral and physiological effects of varying amounts of shade for lactating cows at pasture. J. Dairy Sci. 97:3599-3605. https:// doi.org/10.3168/jds.2013-7649.

Schütz, K. E., A. R. Rogers, Y. A. Poulouin, N. R. Cox, and C. B. Tucker. 2010. The amount of shade influences the behavior and physiology of dairy cattle. J. Dairy Sci. 93:125-133. https://doi .org/10.3168/jds.2009-2416.

Seath, D. M., and G. D. Miller. 1947. Heat tolerance comparisons between Jersey and Holstein cows. J. Anim. Sci. 6:24-34. https:// doi.org/10.2527/jas1947.6124.

Southern California Edison. 2014. Conductive cooling system for dairy farms. ET13SCE7020. Accessed May 15, 2017. https://www .etcc-ca.com/sites/default/files/reports/et13sce7020_conductive cooling_system_for_dairy_farms_report_final.pdf.

St-Pierre, N. R., B. Cobanov, and G. Schnitkey. 2003. Economic losses from heat stress by US livestock industries. J. Dairy Sci. 86(E. Suppl.):E52-E77. https://doi.org/10.3168/jds.S0022 $-0302(03) 74040-5$.

Strickland, J. T., R. A. Bucklin, R. A. Nordstedt, D. K. Beede, and D. R. Bray. 1989. Sprinkler and fan cooling system for dairy cows in hot, humid climates. Appl. Eng. Agric. 5:231-236. https://doi .org $/ 10.13031 / 2013.26507$.

Tresoldi, G., K. E. Schütz, and C. B. Tucker. 2016. Assessing heat load in drylot dairy cattle: Refining on-farm sampling methodology. J. Dairy Sci. 99:8970-8980. https://doi.org/10.3168/jds.2016-11353.

Tresoldi, G., K. E. Schütz, and C. B. Tucker. 2017. Cow cooling on commercial drylot dairies: A description of 10 farms in California. Calif. Agric. 71:249-255. https://doi.org/10.3733/ca.2017a0042.

Tresoldi, G., K. E. Schütz, and C. B. Tucker. 2018a. Cooling cows with sprinklers: Spray duration affects physiological responses to 
heat load. J. Dairy Sci. 101:4412-4423. https://doi.org/10.3168/ jds.2017-13806.

Tresoldi, G., K. E. Schütz, and C. B. Tucker. 2018b. Cooling cows with sprinklers: Timing strategy affects physiological responses to heat load. J. Dairy Sci. 101:11237-11246. https://doi.org/10.3168/jds 2018-14917.

Tresoldi, G., K. E. Schütz, and C. B. Tucker. 2019. Cooling cows with sprinklers: Effects of soaker flow rate and timing on behavioral and physiological responses to heat load and production. J. Dairy Sci. 102:528-538. https://doi.org/10.3168/jds.2018-14962.

Tucker, C. B., D. M. Weary, A. M. de Passillé, B. Campbell, and J. Rushen. 2006. Flooring in front of the feed bunk affects feeding behavior and use of freestalls by dairy cows. J. Dairy Sci. 89:20652071. https://doi.org/10.3168/jds.S0022-0302(06)72274-3.

Turlock Irrigation District. 2010. Live animal testing of conductive cooling systems. Accessed Oct. 30, 2019. Tulare, CA. https://www .TID.org.

USDA. 2014. Dairy 2014, Dairy cattle management practices in the United States. Animal and Plant Health Inspection Service, Veterinary Services, Center for Animal Epidemiology and Health (APHIS-VS-CEAH), Fort Collins, CO. von Keyserlingk, M. A. G., N. P. Martin, E. Kebreab, K. F. Knowlton R. J. Grant, M. Stephenson, C. J. Sniffen, J. P. Harner III, A. D. Wright, and S. I. Smith. 2013. Sustainability of the US dairy industry. J. Dairy Sci. 96:5405-5425. https://doi.org/10.3168/jds .2012-6354.

West, J. W. 2003. Effects of heat-stress on production in dairy cattle. J. Dairy Sci. 86:2131-2144. https://doi.org/10.3168/jds.S0022 -0302(03)73803-X.

West, J. W., B. G. Mullinix, and J. K. Bernard. 2003. Effects of hot, humid weather on milk temperature, dry matter intake, and milk yield of lactating dairy cows. J. Dairy Sci. 86:232-242. https://doi .org/10.3168/jds.S0022-0302(03)73602-9.

\section{ORCIDS}

Grazyne Tresoldi ๑ https://orcid.org/0000-0002-0069-2882

Frank M. Mitloehner (1) https://orcid.org/0000-0002-9267-1180

Cassandra B. Tucker (ํ) https://orcid.org/0000-0002-6014-444X 